\title{
O FEMINISMO NEGRO NO \\ BRASIL E O ENFRENTAMENTO \\ DAS OPRESSÓES DE CLASSE, \\ RAÇA E GÊNERO.
}

\author{
EL FEMINISMO NEGRO EN BRASIL Y EL \\ ENFRENTAMIENTO DE LAS OPRESIONES DE \\ CLASE, RAZA Y GÉNERO.
}

\section{BLACK FEMINISM IN BRAZIL AND THE CONFRONTATION OF CLASS, RACE AND GENDER OPPRESSION.}

Ana Caroline Trindade dos SANTOS

\section{Resumo}

O artigo trata de um apanhado geral da história do feminismo no Brasil e particulariza o surgimento do feminismo negro a partir do histórico dos movimentos sociais feministas na tentativa de apreender as correntes teóricas que direcionavam as leituras e açóes políticas de homens e principalmente de mulheres que lutam contra o racismo e as opressóes de gênero e classe social. Ao tratar sobre as teorias feministas e o feminismo negro é pertinente pautar o formato opressor e discriminatório das sociedades capitalistas, em que os fenótipos são utilizados para justificar atribuiçóes de valores positivos e negativos para a inferiorização de uma raça em relação a outra, se torna compreensivo a perpetuaçáo do racismo em açóes concretas de discriminação racial envolvendo múltiplas violências expressas em guerras, genocídios, perseguição religiosa, desigualdade racial e de gênero. $\mathrm{O}$ que eram consideradas vozes silenciadas e corpos estigmatizados pelo racismo e sexismo se tornam ações políticas de enfrentamento as opressóes demonstrando a eficácia das discussóes de reconhecimento entrelaçadas por

\footnotetext{
${ }^{1}$ Doutoranda em Serviço Social pelo Instituto Universitário de Lisboa - ISCTEIUL; Mestre pela Universidade Federal de Pernambuco. Servidora pública licenciada da Prefeitura Municipal de Aracaju/SE. E-mail: linetrindadess@ yahoo.com.br.
} 


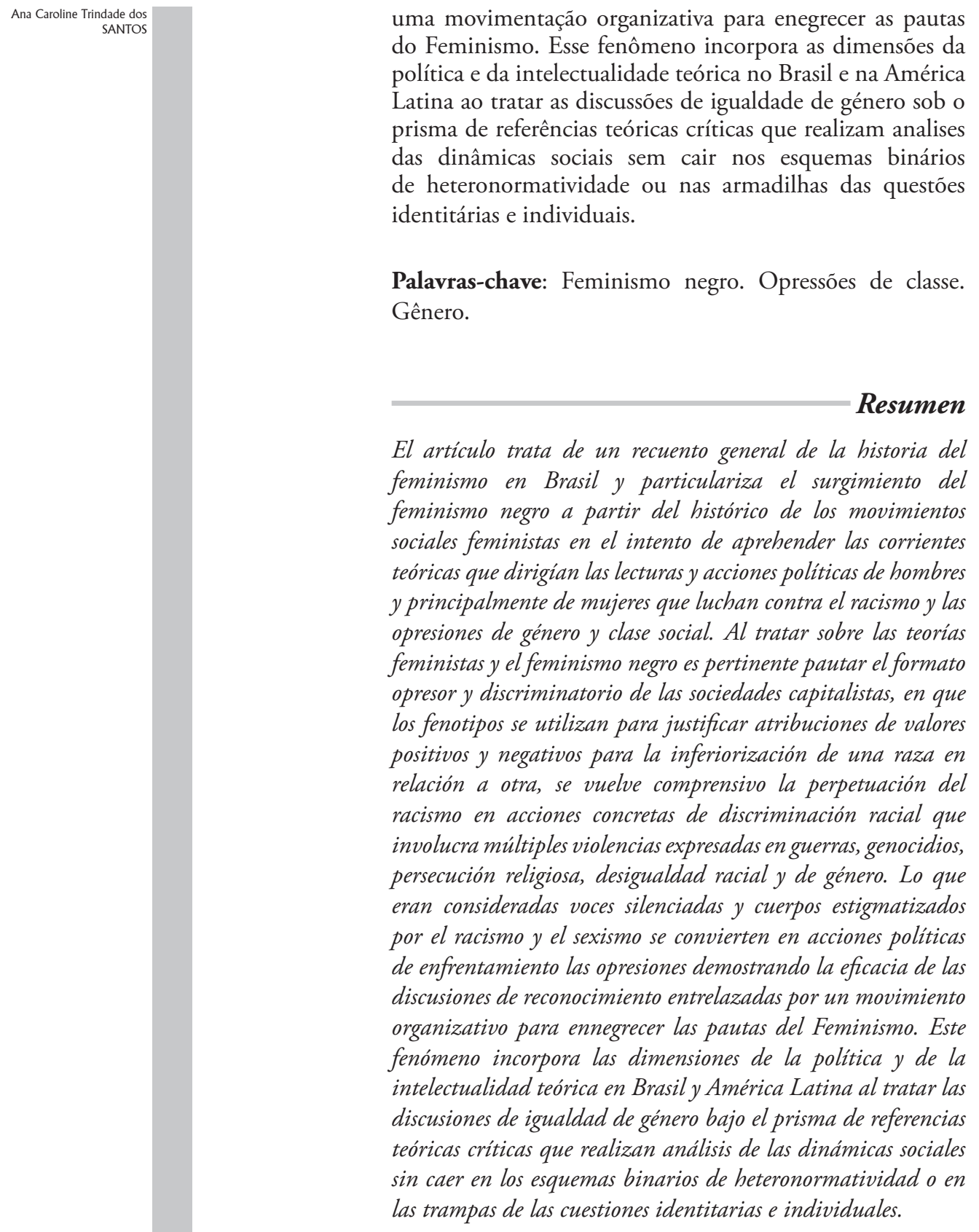

Palabras clave: Feminismo negro. Opresiones de classe. Género. 


\section{Abstract}

The article deals with a general overview of the history of feminism in Brazil and particularizes the emergence of black feminism from the history of feminist and black social movements in an attempt to apprehend the theoretical currents, which direct the readings and political actions of men and especially of women who fight against racism and oppressions of gender and social class. In dealing with feminist theories and black feminism, it is pertinent to set the oppressive and discriminatory format of capitalist societies, in which the phenotypes are used to justify attributions of positive and negative values for the inferiorization of one race to another, it becomes understandable the perpetuation of racism in concrete actions of racial discrimination involving multiple violence expressed in wars, genocide, religious persecution, racial and gender inequality. What was considered silenced voices and bodies stigmatized by racism and sexism became political actions of coping with oppression, demonstrating the effectiveness of the discussions of recognition intertwined by an organizational move to blacken the guidelines of Feminism. This phenomenon incorporates the dimensions of theoretical politics and intellectuality in Brazil and Latin America by treating the discussions of gender equality under the prism of critical theoretical references that perform analyses of social dynamics, without falling into the binary schemes of heteronormativity or in the pitfalls of identity and individual issues.

Keywords: Black feminism. Class oppressions. Gender.

\section{INTRODUÇÃO}

Ao iniciar uma discussão sobre o feminismo negro no Brasil levou-se em conta os aspectos da formação sóciohistórica e a construção do conceito de raça, que nunca foi uma categoria utilizada para mobilizar uma identidade social entre a população negra brasileira e sim, empregada como tentativa de imprimir uma igualdade entre brancos e negros sedimentada na tese da democracia racial. As bases da referida tese estão assentadas na política de branqueamento instaurada

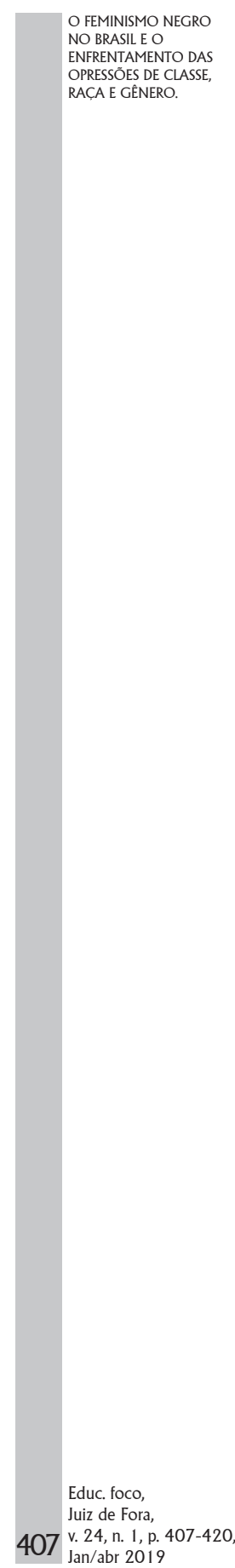

NO BRASIL E O

OPRESSÓES DE CLASSE, RAÇA E GÊNERO. 
pelo Estado brasileiro no pós- abolição da escravidão em 1888 (GUIMARÃES, 2008).

O mito da democracia racial foi disseminado, principalmente, pelos estudos do cientista social Gilberto Freire ao postular que as relaçóes raciais no Brasil foram forjadas no âmbito da democracia baseada na igualdade política e formal entre todos os indivíduos. Ao legitimar a igualdade racial na formaçáo da sociedade e do povo brasileiro estabeleceu o entendimento que as relaçóes sociais e sexuais entre as etnias eram harmônicas e necessárias ao desenvolvimento do país. A tese de Freire tem sido amplamente contestada, principalmente por autores da vertente crítica, como Florestan Fernandes e Otavio Ianni. Esses autores desconstruíram as bases teóricas da tese ao aliar a mesma a uma atitude perversa da burguesia nacional em construir uma ideologia de relaçóes harmônicas entre as classes e no seu interior entre os grupos raciais, e afastar a questão racial do processo de consolidação do capitalismo brasileiro.

Em seus estudos, Martins (2014) destaca que o racismo brasileiro é caudatário da construção social de "raça", conceito esse que foi utilizado para "legitimar a dominaçáo de classe sobre os (as) diferentes: aqueles (as) que não eram brancos (as), europeus (europeias), colonizadores (as), donos (as) do poder" (LUCENA, 2010, apud MARTINS, 2014). Portanto, "raça" serviu e serve à opressão e à espoliação, nessa perspectiva, o racismo não pode ser compreendido se desvinculado dos processos e das estruturas econômicas e políticas subjacentes as relaçóes sociais. (MARTINS, 2014, p. 11).

A crença na existência de raças e suas hierarquizaçóes, fundada numa ideologia de dominação, tende a aprofundar os preconceitos raciais a partir de uma análise com o enfoque na perspectiva de gênero, principalmente nas sociedades cujas estruturas sociais foram marcadas por séculos de escravidão e que formataram papéis sociais para as mulheres negras. Esses papéis foram polarizados entre corpos hipersexualizados, como a mulata, e a preta velha considerada como "mamy", a 
cuidadora dos filhos que não eram seus. Este último simbolizava, através dos seus seios fartos, o afeto e a maternidade, mesmo sendo uma obrigação em cuidar das necessidades dos demais, em particular dos mais poderosos. (HOOKS, 1995 apud MOREIRA, 2011).

A reprodução do racismo estrutural inunda as dimensões das singularidades da construção social do que é se tornar mulher na sociedade em que imperaram o sistema de colonialismo, e para as mulheres negras os estereótipos acima descritos eram as únicas possibilidades para suas vidas. É a partir do movimento feminista que as mulheres negras organizadas questionam as generalizaçóes das pautas de reinvindicaçóes e coadunam com o discurso "Aint'I a Womam?2" proferido pela abolicionista Sojourner Truth, em 1851 na Convenção dos Direitos da Mulher em Akron Ohio/E.U.A., ao problematizar seu lugar na sociedade enquanto mulher negra escravizada.

Connell (2015, p. 126) vai destacar que "o colonialismo teve um impacto massivo e quase sempre altamente destrutivo nas ordens de gênero das sociedades colonizadas. As populaçóes de colonos também precisavam negociar mudanças em seu modo de vida.", a perversidade do sistema colonial resulta na negação da mulher negra enquanto ser social. A partir de uma leitura crítica sobre o histórico das discussóes de gênero entrelaçadas com classe e raça é que o discurso de Sojourner Truth será resgatado e fará sentido no interior do feminismo negro.

Será apenas na Segunda fase do Feminismo, em que a normatização da sexualidade passa a ser encarado como um produto histórico das relaçóes de poder entre homens e mulheres, que o feminismo negro desponta no cenário brasileiro, ao acompanhar as discussões das feministas norteamericanas que pautaram as teorias de gênero e aprofundaram as particularidades da mulher negra num contexto de cruzamento dos marcadores sociais de raça, classe e gênero.

2 "E eu não sou uma mulher?"

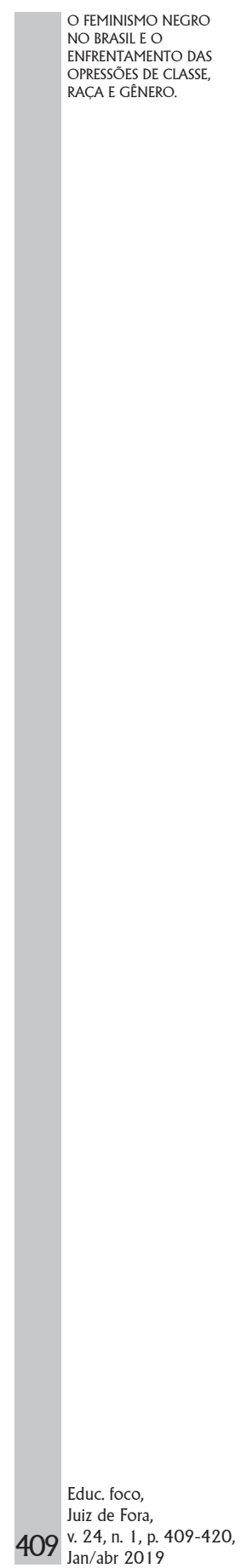

NO BRASIL E O

RACA E CENEROS ACCA E GÊNERO. 
O Movimento Feminista no Brasil e o despontar do Feminismo Negro

No Brasil o direito político de votar e ser votada só será exercido pelas mulheres em 1932, com a luta de um grupo de feministas sufragistas brasileiras que lutaram com indignação e constataram na prática as degradantes desigualdades provocadas pela heteronormatividade na sociedade brasileira. Mesmo com a luta isolada de mulheres, oriundas de familias ricas escravagistas ou comerciantes, com formação acadêmica e inserção no mundo das artes através da literatura, do teatro e da música, nomes como o de Bertha Lutz (1884 - 1976), Almerinda Farias Gama (1899 - 1992), Carmem Portinho (1903- 2001) , Maria Luisa Bittencourt (?), Josefina Álvares de Azevedo (1851 - ?), Jerônima Mesquita (1880 - 1972), Chiquinha Gonzaga (1847 - 1935), Natércia da Silveira (?). No cenário da Nova República brasileira, foi possível encontrar na historiografia as primeiras feministas negras eleitas pelo voto direto para representar as mulheres como Antonieta de Barros (1901-1952) de Santa Catarina, sendo a primeira deputada negra do Brasil. Ao longo dos anos e dos processos históricos de luta pela inserção da mulher na esfera política, este espaço se constituiu como palco para o protagonismo de mulheres negras que disputaram a pauta geral do feminismo.

Moreira (2011) chama a atenção para a roupagem liberal da fase sulfragista do movimento feminista brasileiro, que desde o seu surgimento nos anos 20 do secúlo passado até a decada de 1960, período que antecede a ditadura militar no Brasil, as mulheres organizavam as lutas com objetividade voltada para a conquista da cidadania, do reconhecimento de que a não participação nas instâncias de decisão era resultado da sua condição de mulher imposta pelo patriarcado.

As críticas realizadas a primeira fase do feminismo brasileiro não dissoam das críticas gerais aos resultados das vitórias das mulheres no período sulfragista, mesmo com experiências exitôsas no campo da política, em ter sempre mulheres na institucionalidade partidária, a legitimação 
da heteronormatividade branca que reproduz relaçôes de dominação nas esferas políticas, econômicas e socioculturais permanece até a atualidade e as particularidades das questóes feministas negras só tomam relevância a partir do questionamento político das generalizaçôes das lutas pautadas na realidade das mulheres brancas, oriundas das classes alta e média, ocidentalizadas e eurocêntricas.

As movimentaçóes políticas da sociedade a partir de 1960 trouxeram para as correntes feministas questionamentos das características centrais da modernidade capitalista que a social-democracia tinha naturalizado até então: repressão sexual, sexismo e heteronormatividade; materialismo, cultura corporativa e a "ética do sucesso"; consumismo, burocracia e "controle social". (Fraser, 2007, p. 295). O acordo entre o capital e trabalho, por meio do Welfare State, demonstrava os primeiros sinais de limitaçóes e as críticas analisadas sob a perspectiva de gênero problematizaram o paternalismo do Estado do bem-estar social e a família burguesa, os feminismos expuseram o profundo androcentrismo da sociedade capitalista. (ibdem)

No movimento feminista brasileiro em paralelo ao feminismo liberal surgia movimentos de mulheres operárias que se organizavam em torno da luta contra a opressão sexista exercida por patróes e alinhava as discussóes do feminismo com a exploração da força de trabalho e à dominação sexual. Esse cenário de discussóes é aprofundado em meio a conjuntura de reabertura política e democrática que marca as décadas posteriores a 1980. O feminismo de classe, como ficou conhecido a corrente teórica que embasava as açôes políticas dos movimentos de mulheres, passou a concentrar feministas acadêmicas que se apropriam das demandas políticas e sociais das mulheres organizadas e tocam suas pesquisas teóricas sobre os temas que perpassam o cotidiano das opressóes sexistas a

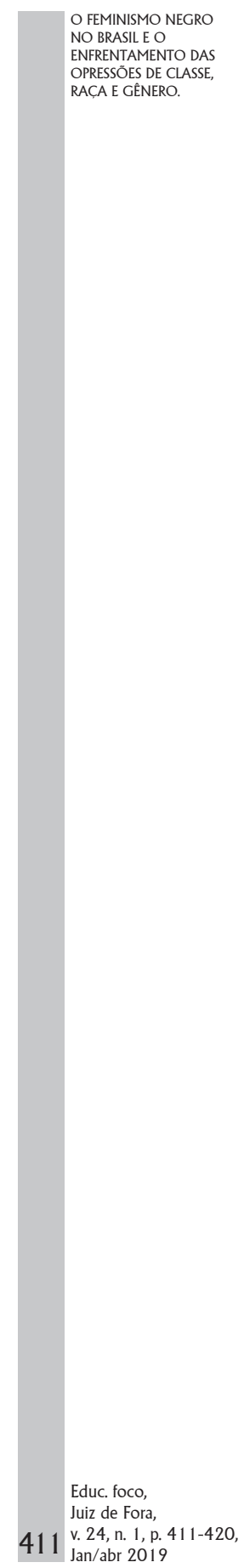


exemplo da violência doméstica ${ }^{3}$ e familiar contra a mulher e desigualdade de gênero reproduzida no mercado de trabalho.

Nesse intermédio temos as pesquisas de feministas acadêmicas como Safiotti que nos seus estudos "examinou a divisão sexual do trabalho nos diferentes setores da produção; as condiçôes de trabalho das mulheres no campo; a estrutura do emprego doméstico etc. Na contramão dos que acreditavam que o desenvolvimento do capitalismo traria maior igualdade, demonstrou que as mulheres continuariam inseridas de forma precária neste sistema de produção.” (GONÇALVES, 2016). Os escritos de Safiotti são reconhecidos internacionalmente e enquadrados como um importante avanço teórico aos dilemas impostos ao feminismo na destruição do patriarcado. Segundo Connell (2015, p. 134) a publicação do livro "A mulher na sociedade de classes" por Safiotti trouxe "uma teorização marxista-feminista sofisticada sobre o sexo como forma de estratificação social e um balanço detalhado e embasado em estatísticas da divisão sexual do trabalho, da economia política da família e da educação das mulheres."

Mesmo diante de uma análise crítica sobre o patriarcado e as reproduçóes de desigualdade de gênero, a postura do feminismo em defender um "projeto universal de mulher" revelou o formato racista do movimento sobre as particularidades das questóes raciais que envolvem as mulheres negras na sociedade capitalista. Essa crítica tem exponencial reprodução com as feministas norte-americanas no limiar dos anos de 1970 e reverbera sobre o ocidente encontrando no Brasil terreno fértil para a contestação de que as "mulheres não são inferiores aos homens, mas não são iguais a eles e que a diferença, longe de representar uma desvantagem, contem potencial enriquecedor de crítica da cultura.”. (OLIVEIRA, 2004 apud MOREIRA, 2011).

\footnotetext{
${ }^{3}$ Somente em 2006 com a promulgação da Lei Maria da Penha é que teremos a amplitude de identificar as violências acometidas as mulheres, em seu artigo 70 temos a tipificação de cinco formas de violência, quais sejam: física, psicológica, patrimonial, sexual e moral.
} 
Bairros (1995) ao analisar teoricamente os feminismos trata de alargar o pensamento das feministas socialistas que ofereceram alternativas para explicar a interseção entre gênero, raça, classe e orientação sexual, mesmo mantendo a experiência de ser mulher como elemento universal para definir opressão sexista. Os demais marcadores sociais passam a formular a dupla ou tripla dimensão de opressão o que gerou margens para compreensóes de que existem grupos mais ou menos discriminados e resultou na "incapacidade das correntes feministas de oferecer uma formulação que evidenciasse como somos todas e todos afetados pelo sexismo em suas diversas formas: homofobia, machismo e a misoginia" (BAIRROS, 1995). Ao atrelar sua análise de interseção entre os marcadores sociais, a autora usa o exemplo da percepção do homem como o provedor central da família, ou o que ocupa os melhores postos de trabalho ou ainda o iniciador das relaçóes amorosas o que pode ser controvertida ao utilizar o racismo como elemento de reconfiguração do papel do homem negro na sociedade.
Como salientado no parágrafo anterior homens também vivenciam raça através de gênero, mas ao contrário das mulheres não percebem os efeitos opressivos do sexismo sobre sua própria condição. Daí tenderem a confundir o combate às desigualdades de gênero com antagonismo entre homens e mulheres ou com uma tentativa de acabar com privilégios da condição masculino que eu duvido possam ser desfrutados plenamente por homens negros numa sociedade racista. Até por isto o movimento negro um dos poucos espaços que se oferecem para a expressão plena de pessoas negras também é palco para o exercício de um sexismo que não poderia manifestar se em outras esferas da vida social especialmente aquelas dominadas por (homens) brancos. (BAIRROS, 1995, p. 461).

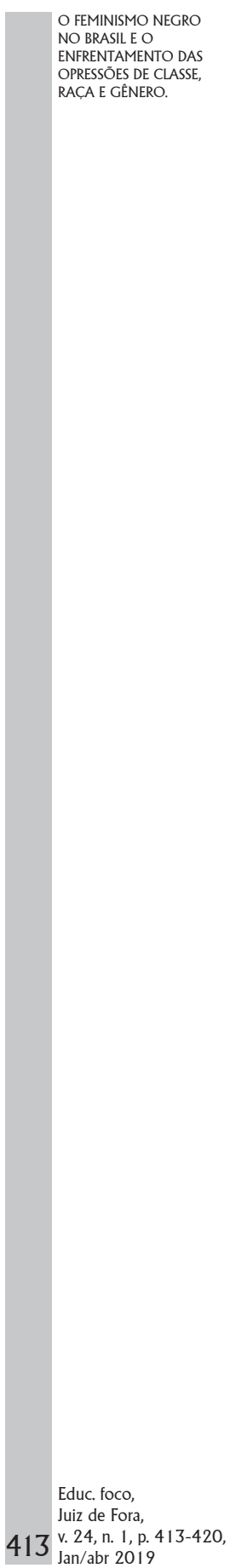


A citação acima de Bairros coaduna com a tese defendida por Carneiro (2003) de que o racismo rebaixa os gêneros por meio de privilégios que advém da exploração e exclusão dos gêneros negros considerados subalternos, "a variável racial produziu géneros subalternizados, tanto no que toca a identidade feminina estigmatizada (mulheres negras), tanto nas masculinidades subalternizadas (homens negros) com prestígio inferior ao gênero feminino do grupo racialmente dominante."(Carneiro, 2003, p. 119). É com essas demarcaçóes que entramos nos principais apontamentos históricos do feminismo negro brasileiro, que conta com a resistência de mulheres negras de diversas geraçóes e camadas sociais.

O surgimento do movimento feminista negro no Brasil, como já foi acima citado tem sua demarcação histórica no final da década de 70 e ao curso dos anos 80 acontece de forma paralela a reorganização dos movimentos sociais que reivindicam o fim do racismo e da discriminação contra a população negra na reabertura democrática com a derrota de 21 anos de ditadura militar. $\mathrm{O}$ ressurgimento do movimento negro no Brasil deu-se por volta dos anos de 1970 do século XX, a partir da movimentação da sociedade civil organizada contra a ditadura e na reivindicação pela volta da democracia. Segundo Neves (2005) em meio aos processos de mobilizaçáo dos movimentos negros deve-se pautar a discussão do reconhecimento e da redistribuição no interior da questão racial no Brasil.

As discussóes sobre o reconhecimento foram propostas pelas entidades negras no seu processo de reorganização ainda na década de 1960 ao utilizar o debate da identidade e do reconhecimento como recursos para mobilização. (Neves, 2005). As teorias do reconhecimento estão ligadas ao processo histórico da modernidade em que seus pilares são constituídos pela liberdade e igualdade. Nos sistemas liberais democratas essas duas vertentes foram transmutadas em igualitarismo liberal e a grande bandeira de reivindicação pela liberdade 
passou a mover os movimentos sociais negros no século XIX e XX pelo reconhecimento da cidadania e da justiça social das classes populares. Fraser (2002) sugere que as lutas feministas não devam demonstrar desatenção às lutas sociais, a autora sugere que haja uma articulação entre as políticas de redistribuição e as políticas de gênero já que "questóes distributivas e lutas de reconhecimento envolvem questóes como diferença, identidade e representação.”.

Seguindo as discussóes de reconhecimento e identidade entre os anos de 1985 a 1995 diversos encontros nacionais e regionais reuniram mulheres negras organizadas em uma pluralidade de movimentos sociais (partidários, classistas e da sociedade civil organizada) fruto da intersecção entre os movimentos negro e feminista e seus pontos de tensáo acerca das demandas étnico-racial e de gênero que assolava o cotidiano das mulheres brasileiras (MOREIRA, 2011). Será no interior do Movimento Negro que surgiram as inquietaçóes sobre a secundarização da mulher no protagonismo das lutas antiraciais e a necessidade de uma construção identidade negra em uma sociedade marcada pelo mito da democracia racial.

A questão da formação de uma identidade da mulher negra e feminista se tornou uma pauta prioritária no processo de organização, pois, além de lutar contra os estereótipos vinculados ao corpo feminino negro, pulverizado pelos papéis de mulata ou de "mamy" em decorrência do que foi ideologicamente demarcado, travava batalhas internas no movimento feminista ao banalizar as demandas cotidianas dessas mulheres. Bairros (2008) destaca a seguinte questáo,

O feminismo traz uma contribuição importantíssima, do ponto de vista de uma visão de mundo. Mas as feministas também são formadas para desconhecer as desigualdades raciais. Formadas para pensar o Brasil como uma democracia racial. E aí, contraditoriamente, ainda que o movimento feminista consiga perceber em que nível a diferença de sexo é utilizada na reprodução das desigualdades, não consegue perceber como as diferenças raciais são

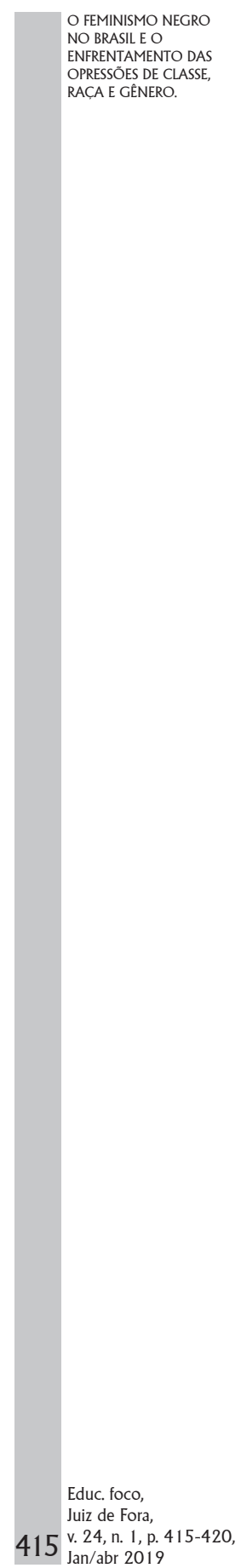



mecanismos de discriminação racial. (BAIRRO, 2008, apud MOREIRA, 2011, p. 67).

Um ponto de tensão que o feminismo negro trabalhou no interior de suas organizaçóes foi tornar a pauta feminista compreensível para as mulheres negras, tendo em vista que as conquistas dos movimentos feministas na esfera da produção em relação ao mercado de trabalho, no que diz respeito à profissionalização, a condiçôes salariais os tipos de empregos e vínculos laborais. As pesquisas realizadas por feministas acadêmicas reforçam a necessidade de análises interseccionais entre gênero, classe e raça, ao observar às taxas de emprego é possível identificar que a ocupação da população negra nos ramos de atividades está relacionada às funçóes de menor prestígio social como os serviços domésticos, a construção civil, na indústria têxtil e nos serviços de limpeza. Martins (2012) destaca que,

(...) embora os trabalhadores sejam afetados de um modo geral pela realidade de precarização e informalidade nas relaçóes de trabalho são os grupos que historicamente se encontravam em desvantagem social que se inserem em maior proporção nas ocupaçóes/trabalhos precários e informais. Daí porque (entre 1995 a 2006) na condição assalariada com carteira assinada havia uma presença maior de trabalhadores brancos $(36,8 \%)$ do que entre pretos e pardos $(28,5 \%)$; entre os homens brancos $(39,8 \%)$ do que pretos e pardos (33\%); e entre as brancas $(33 \%)$ do que as pretas e pardas $(22 \%)$. (MARTINS, 2012, p. 463)

As diferenças étnico-raciais perpassam as diversas esferas que compóem a sociedade inclusive na dimensão do trabalho, se os dados acima citados demonstram uma desigualdade na inserção dos negros em ocupaçóes formais, ao analisarmos os dados estatísticos com relaçáo ao desemprego o traço do preconceito racial se torna mais emblemático. Martins (2012) destaca que em 1995 o número de pretos e pardos correspondia 
a $48,6 \%$ do total dos desocupados, sendo que desse universo 25,3\% eram homens e 23,3\% eram mulheres; em 2006 esse quantitativo aumenta para $54,1 \%$, sendo $23,9 \%$ de homens e $30,8 \%$ de mulheres pretas e pardas.

Mais uma vez é possível concordar com Carneiro (2003, p. 119) ao afirmar que a variável racial produz gêneros subalternizados e para as mulheres negras "atingirem os mesmos níveis de desigualdades existentes entre homens e mulheres brancos significaria experimentar uma experimentar uma extraordinária mobilidade social, uma vez que os homens negros, na maioria dos indicadores sociais encontram-se abaixo das mulheres brancas.".

A incorporação do feminismo das discussóes sobre exploração da força-de-trabalho feminino, nas esferas privada e pública, fruto de uma construção teórica no referencial crítico requer também aprofundamento do debate de gênero, reprodução e sexualidade, na teoria da Intersecionalidade propagada pela advogada norte-americana Kimberlé Crenshaw, o conceito sociológico vai estudar as interaçôes nas vidas das pessoas negras inseridas nos grupos denominados de "minorias" entre diversas estruturas de poder e segue como uma consequência de diferentes formas de dominação e/ou discriminação.

Segundo Hirata (2014) a problemática da interseccionalidade foi desenvolvida num quadro de interdisciplinaridade que focaliza sobretudo os marcadores sociais de raça e gênero que aborda de forma periférica as questóes envolvendo classe e sexualidade. Ou seja, "a interseccionalidade é uma proposta para levar em conta as múltiplas fontes de identidades embora não tenha a pretensão de propor uma nova teoria globalizante de identidades." (HIRATA, 2014, p. 62).

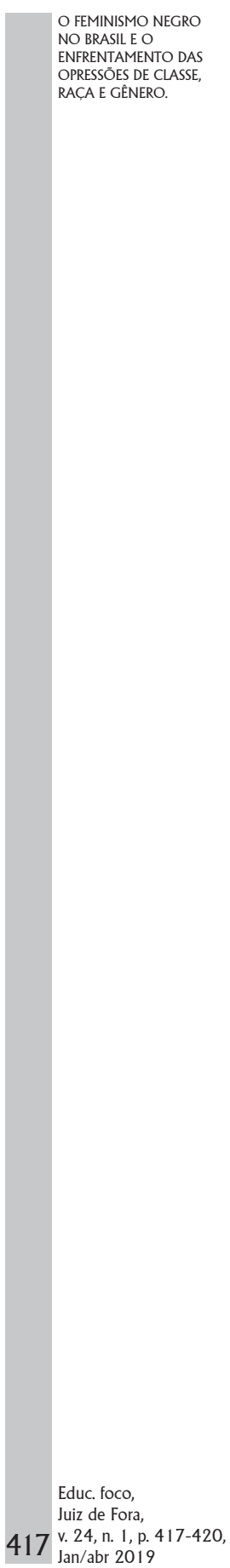


Ana Caroline Trindade dos SANTOS

Educ. foco,

Juiz de Fora, v. 24, n. 1, p. $418-420$, Jan/abr 2019418

\section{CONSIDERAÇÓES FINAIS}

Ao tratar sobre as teorias feministas e o feminismo negro brasileiro é pertinente pautar o formato opressor e discriminatório nas sociedades capitalistas, em que os fenótipos são utilizados para justificar atribuiçóes de valores positivos e negativos para a inferiorização de uma raça em relação a outra, se torna compreensivo que o racismo se perpetue em açôes concretas de discriminação racial envolvendo múltiplas violências expressas em guerras, genocídios, perseguição religiosa, desigualdade racial e de gênero.

$\mathrm{O}$ que eram consideradas vozes silenciadas e corpos estigmatizados pelo racismo e sexismo se tornam açóes políticas de enfrentamento as opressóes raciais e de gênero demonstrando a eficácia das discussóes de reconhecimento entrelaçadas por uma movimentaçáo organizativa de Enegrecer o Feminismo. Esse fenômeno incorpora as dimensôes da política e da intelectualidade teórica no Brasil e na América Latina ao tratar as discussóes de igualdade de género sob o prisma de referências teóricas críticas que realizam analises das dinâmicas sociais sem cair nos esquemas binários de heteronormatividade ou nas armadilhas das questóes identitárias e sua subjetividade individual.

\section{Para nós negros é necessário enfrentar esta questão não apenas porque a dominação patriarcal conforma relaçôes de poder nas esferas pessoal, interpessoal e mesmo íntimas, mas também porque o patriarcado repousa em bases ideológicas semelhantes às que permitem a existência do racismo a crença na dominaçáo construído com base em noçóes de inferioridade e superioridade. (BAIRROS, 1995, p. 462)}

Se tornou responsabilidade das teorias feministas aceitar e discutir que "género, classe e raça não são formas de opressóes distintas e cumulativas, mas sim que o género é construído nas e através das diferenças de raça e de classe, e vice-versa." (LOVELL, 2002, p. 314). Nas particularidades da sociedade brasileira se faz necessário apreender que as questóes de gênero envolvem a superação do racismo, da homofobia e da misoginia. 


\section{REFERÊNCIAS}

BAIRROS, L. Nossos feminismos revisitados. Estudos Feministas, v. 95, n. 2, p. 458-463, 1995.

BAIRROS, L. A mulher negra e o feminismo. In: COSTA, A. A. A.; SARDENBERG, C. M. B. O Feminismo no Brasil: reflexōes teóricas e perspectivas. Salvador: UFBA/NEIM, 2008.

CARNEIRO, S. Mulheres em Movimento. Estudos Avançados, v. 17, n. 49, p. 118-132, 2003.

CONNELL, R.; PEARSE, R. Gênero: uma perspectiva global. Tradução e revisão técnica de Marília Moschokovich. São Paulo: Versos, 2015.

FRASER, N. (2007). Mapeando a imaginação feminista: da redistribuição ao reconhecimento e à representaçăo. Estudos Feministas, v. 15, n. 2, p. 291-308, 2007.

GUIMARÁES, A. S. A. Preconceito racial: modos, temas e tempos. - São Paulo: Cortez, 2008.

HOOKS, B. Intelectuais Negras. Estudos Feministas, v. 3, n. 2, p. 464-478, 1995.

LOVELL, T. Teoria Social Feminista. In: BRYAN S. T. (ed.). Teoria Social (pp. 313-346). Lisboa: Difel, 2002.

MARTINS, Tereza Cristina Santos. O negro no contexto das novas estratégias do capital: desemprego, precarizaçấo e informalidade. Serviço Social e Sociedade, v. 111, p. 450-467, jul./set, 2012.

MARTINS, Tereza Cristina Santos. Racismo, questão social e serviço social: elementos para pensar a violaçáo de direitos no Brasil. Revista Inscrita, n. 14, p. 11-17, 2013.

MOREIRA, N.R. (2011). A Organização das Feministas Negras no Brasil. Vitória da Conquista: Ediçóes UESB, 2011. 
NEVES, P. S. C. Luta anti-racista: entre o reconhecimento e a redistribuição. Revista Brasileira de Ciências Sociais, v. 20, n. 59, p. 81-96, outubro/2005.

VASCONCELOS, Pedro. Categorização, Identidade e Sexualidade: notas sobre a dominação. In: Ana Paula Marques et al. (coord.), Formas Identitárias e Modernidade Tardia (pp. 51-70). Braga:ICS - UM, 2014. 